\title{
Ação Política Híbrida e a Dissolução da Cidadania
}

\author{
[Hybrid Political Action and the Dissolution of Citizenship]
}

\author{
Edson Teles»
}

\begin{abstract}
Resumo: O objetivo do artigo é reconhecer e analisar determinadas reflexões conceituais acerca da ação política que apresentem as formas mecânicas ou funcionais, indicando estratégias do agir autônomas em relação aos aspectos discursivos. Nossa hipótese é a de que categorias tradicionais, tais como a soberania, a representação, as instituições do Estado e da sociedade civil são insuficientes como instrumentos de compreensão do político. A questão central é a de que os regimes de produção de subjetividades encontram sua maior eficácia na intersecção ou nas fronteiras entre os modos discursivos e os funcionais. Busca-se introduzir aspectos de certa filosofia contemporânea que, antecedendo o capitalismo de vigilância e suas tecnopolíticas, já se debruçava sobre a fabricação e as máquinas enquanto elementos dos processos de condução das vidas individuais e coletivas.
\end{abstract}

Palavras-chave: Discurso. Estratégia. Máquina. Subjetivação. Fabricação.

\begin{abstract}
The objective of the article is to recognize and analyze certain conceptual reflections about political action that present mechanical or functional forms, indicating autonomous strategies for acting in relation to discursive aspects. Our hypothesis is that traditional categories, such as sovereignty, representation, state institutions and civil society are insufficient as instruments for understanding the political. The central issue is that subjectivity-producing regimes find their greatest effectiveness at the intersection or boundaries between discursive and functional modes. It seeks to introduce aspects of a certain contemporary philosophy that, prior to surveillance capitalism and its technopolitics, already focused on fabrication and machines as elements in the processes of conducting individual and collective lives.
\end{abstract}

Keywords: Discourse. Strategy. Machine. Subjectification. Fabrication.

${ }^{*}$ Professor de filosofia política da Universidade Federal de São Paulo (Unifesp). Doutor em filosofia pela Universidade de São Paulo (USP). E-mail: edson.teles@unifesp.br. ORCID: https://orcid.org/0000-0002-6673-2234. 


\section{Introdução}

Há a produção, no mundo contemporâneo, de uma espécie de economia política, com seus dispositivos e mecanismos estratégicos, cuja função seria a articulação entre os modos capitalistas de mercado e o governo das subjetividades. Diferentes modos de interação entre pessoas e tecnologias são experimentados cotidianamente reforçando a sobreposição das estratégias funcionais nas subjetividades e nas estruturas sociais indicando outras formas da política. A interconexão entre máquinas e humanos parece borrar os limites entre o discursivo e o funcional.

Trata-se de compreender como ocorrem os regimes de produção de subjetividades presentes nas formas de governo da vida. A sociedade capitalista nos lança num duplo sistema de controle. Por um lado, somos "humanizados" por meio da construção de indivíduos com papéis previamente estabelecidos. Num outro viés, não "humanizado", somos controlados por um agenciamento sem a divisão sujeito e objeto, natureza e cultura, a coisa e sua representação, público e privado, humano e não humano.

Esse lugar híbrido indica algo que nos parece se constituir nas bordas do político, em territórios periféricos. Pensamos não em subjetividades enquanto algo acabado, mas em sua produção. É um processo cultural e social, uma certa economia da vida que as produz. Traba- lhamos com a hipótese de que a forma central com que as relações de poder atuam diz respeito ao governo, suas técnicas, tecnologias e funções, bem como seus regimes de produção de subjetividades.

Como pensar uma política que transborde os limites da representação? Uma ação cujo funcionamento extrapole os significados expressos pelas falas? Como lidar com os conflitos sociais e políticos aparentemente restritos às representações da linguagem e da palavra inscritas na lei? Como agir nos limites do Estado de Direito se a ação o transborda?

A política, stricto sensu, seria a capacidade humana de lidar com a sociabilidade, seus saberes e experimentações, suas significações e produções, de modo a permitir o entendimento entre as diversas singularidades que nos compõem. Em uma abordagem clássica da teoria política o elemento de compreensão dessas interações seria a relevância do discursivo como forma de os indivíduos, quando em condição plural, serem capazes de se comunicarem e estabelecerem acordos. Entretanto, no mundo contemporâneo, a filosofia política se depara frequentemente com a questão sobre como os indivíduos se relacionam, interagem e se entendem além do modo discursivo.

As subjetividades e seus regimes de produção parecem nos mostrar que a experiência contemporânea do ser humano, ao menos nas formas ocidentais 
de sociabilidade, não se realiza em esferas distintas entre o político e o não político, o discursivo e o funcional, o público e o privado, as instituições e a rua. Antes, a própria efetivação das relações de poder ocorre mediante mecanismos e técnicas de governo em uma ampla dimensão, tornando as vidas, os corpos e as relações entre eles tão artificiais quanto biológicas. Através da hibridização das estratégias discursivas com as funções técnicas e tecnológicas a política vem cada vez mais aparecendo como o processo e o resultado de ações maquínicas.

Salientamos que este artigo não está voltado à explicação exaustiva dos argumentos dos autores mobilizados, mas objetiva introduzir as reflexões sobre a ruptura com os ecos de uma tradição política moderna, representacional, discursiva e soberana. Pretendemos utilizar os conceitos enquanto ferramentas ${ }^{1}$ que nos auxiliem a perceber, dentro da filosofia contemporânea, aspectos que apontem para a hibridização da ação política e das práticas sociais (Latour, 2013).

\section{Entre a tradição e o mundo fabricado}

Para Hannah Arendt, autora cuja obra é caracterizada pelo elogio das formas dialógicas, verbais e discursivas, as marcas da política "já não se prestam à expressão normal no discurso e no pensamento" (2010, p. 3).

No Prólogo de sua obra $A$ condição humana, publicado em 1958, Arendt usou de figuras da "ficção científica" para expor a condição política fabricada no "mundo moderno" "2. Segundo a autora, apesar de que à ficção científica, "infelizmente, ninguém deu até agora a atenção que merece como veículo dos sentimentos e desejos", ela se configura como apropriada para alimentar a ima-

\footnotetext{
${ }^{1}$ Experimentamos a reflexão sobre o conceito enquanto ferramenta, com a qual ensaiamos a escrita sobre questões contemporâneas, mediante o auxílio à leitura de uma entrevista de Félix Guattari, na qual ele discorre sobre a obra escrita junto com Deleuze: "Nosso problema não era esse, mas sim chegar a um acordo sobre nossas ferramentas conceituais. Propus essa formula há muito tempo, inclusive Michel Foucault, aliás, usou essa noção de ferramenta conceitual, ou seja, que era válido tomar uma parte, até mesmo uma palavra, uma expressão, uma sutileza conceitual na obra de alguém para tentar fazer um certo tipo de montagem" (Uno, 2016: p. 43-44). Entendemos que a apresentação parcial dos conceitos dos autores não indica o esgotamento da temática da hibridização nas obras trabalhadas no artigo, mas visa antes fazer emergir o fenômeno de uma ação não apenas discursiva, buscando fundamentalmente alargar o conceito da política e, com isso, contribuir para o investimento em análises que o percebam além dos mecanismos do Estado de Direito e da democracia liberal.

${ }^{2}$ Hannah Arendt distingue mundo moderno de era ou época moderna. O mundo moderno "veio à existência através da cadeia de catástrofes deflagrada pela Primeira Guerra Mundial. A ruptura com os valores tradicionais, por meio da crítica dos pensadores do século XIX, é o evento que separa a época do mundo modernos" (1997, p. 54).

${ }^{3} \mathrm{O}$ recurso de Hannah Arendt à ficção científica participa de seus argumentos sobre as dificuldades inerentes à política discursiva trazidas pelos avanços técnicos e tecnológicos. Em várias passagens de sua obra o tema aparece. Em A promessa da política a autora expõe a relação entre "o totalitarismo e a bomba atômica", duas experiências que suscitaram a "pergunta sobre o significado da política em nossa época. (...) Ignorá-las é como nunca ter vivido no mundo que é o nosso mundo" (2008, p. 163). Os avanços da ciência participam da crise da tradição nas práticas sociais e no pensamento, como anunciado em seu livro de coletânea de ensaios, Entre o passado e o futuro, no texto "A conquista do espaço e a estatura humana", de 1963. Nele a autora relaciona a questão da tecnologia aos problemas políticos e cotidianos, apontando as novas conquistas da ciência como um problema político: "a questão levantada dirige-se ao leigo e não ao cientista, e inspira-se na preocupação do humanista para com o homem, distintamente da preocupação do físico com a realidade do mundo físico" (1997, p. 326). Sobre a presença das criações da ficção científica na obra de Hannah Arendt
} 
ginação e as análises políticas? Pois, é o "artifício humano do mundo", as técnicas e tecnologias de condução da ação, que realizam e afirmam "aquilo que os homens haviam antecipado em sonhos" (Ibidem: p. 2).

A questão arendtiana, diante das máquinas que falam e pensam por nós (Ibidem: p. 4), ou conosco, se refere à perda da profundidade do pensamento e, com isso, ao perigo de sermos incapazes de compreender os acontecimentos que podemos produzir. Essa espécie de "alienação do mundo" seria identificável, segundo Arendt, no divórcio entre os mecanismos e funções da ação política e a cada vez maior capacidade de praticar o ato sem reflexão, como que funcionando ao modo de "criaturas desprovidas de pensamento à mercê de qualquer engenhoca tecnicamente possível" (Ibidem: p. 4). A perda de importância do discurso nas relações de poder é em si um problema político contemporâneo, pois "sempre que a relevância do discurso está em jogo, as questões tornam-se políticas por definição" (Ibidem: p. 4). Porém, parece ser fato, para a autora, que há uma série de sociabilidades, interações e relações de forças "que de modo algum podem ser retraduzidas em discurso" (Ibidem: p. 4).

Hannah Arendt analisa como a cada vez maior presença do elemento máquina e das automações vêm transformando por completo as tradicionais atividades humanas. Em uma sociedade na qual o trabalho, em suas várias formas conhecidas, dá lugar às "fabricações", o indivíduo se torna parte de um mecanismo maior cujos elementos, no entanto, funcionam independentemente de um comando central: seria o "advento da automação" (Ibidem: p. 5). Ao fazer a categorização das atividades humanas 4 , Arendt discorreu sobre a "obra", atividade humana correspondente ao "mundo 'artificial' das coisas", cujos territórios abrigam "cada vida individual, embora esse mundo se destine a sobreviver e a transcender todas elas" (Ibidem: p. 8).

É como se estivéssemos em uma política na qual a vida seria apenas um meio de fazer funcionar um regime de produção cujo produto não faria distinção entre o biológico e a coisa, entre o natural e o artificial. Assim, os indivíduos seriam não só o meio, mas também o produto da fabricação. Per-

\footnotetext{
e suas relações com a literatura do gênero, ver "Hannah Arendt e a ficção científica”, de Edgar Lyra (2011).

${ }^{4}$ Hannah Arendt (2010) compreende o agir de três formas: com a natureza; com os objetos feitos pela mão humana; e, entre as pessoas. Essas relações não são pensadas como um quadro esquemático e fixo, mas como fenômeno complexo e interativo, no qual as atividades se apresentam relacionadas umas com as outras, complementando-se. As atividades que compõem a vita activa, como Arendt as nomeou, são: trabalho, fabricação e ação. Cada uma dessas atividades corresponde a uma concepção do humano, ora descrito enquanto animal laborans, quando o agente se encontra aprisionado às necessidades biológicas e trabalha para prover sua subsistência; ora como homo faber, o indivíduo enquanto fabricante de artefatos duráveis, construindo um mundo por meio do domínio de uma técnica; e, ora como zoon politikon, o agente da política, caracterizado pelo relacionamento com os outros na esfera pública. Hannah Arendt diferencia trabalho, fabricação e ação pelo produto ou resultado final obtido; pelo tempo empreendido na sua realização; pelo espaço ocupado ao colocar em prática o ato; e, através do comportamento humano ao se expressarem.
} 
deria em valor as verdades sobre uma política das esferas de diálogos e trocas discursivas com o fito de persuadir o outro. Trata-se mais de produzir o corpo-máquina capaz de funcionar, e fazer funcionar, as engrenagens das relações agonísticas.

Sabemos que para a autora, a "atividade política por excelência” é a que ocorre diretamente na pluralidade discursiva das expressões humanas singulares. Entretanto, a própria Arendt discorre sobre o quanto a atual condição humana "nasceu com as primeiras explosões atômicas" (Ibidem: p. 7) e se encontra profundamente apartada de toda uma tradição ocidental. "O que quer que toque a vida humana ou mantenha uma duradoura relação com ela assume imediatamente o caráter de condição da existência humana" (Ibidem: p. 11).

Seguindo a imagem do objeto artificial e ficcional $!^{5}$ que parecia realizar o desejo de libertar "os homens de sua prisão na Terra” (Ibidem: p. 1), Hannah Arendt compara as condições atu- ais da vida política a "uma emigração dos homens da Terra para algum outro planeta" (Ibidem: p. 11). Com clareza de análise ela apresenta a condição de já estarmos habitando outro planeta, contudo, em plena ocupação terráquea. O planeta que deixamos para trás é o da tradição de um pensamento político que insiste em nos prender às antigas amarras discursivas quando a política e seus mecanismos já operam, com transformações ocorrendo em grande velocidade, através de funções e estratégias ${ }^{6}$.

A "alienação do mundo, em sua dupla fuga da Terra para o universo e do mundo para o si-mesmo" (Ibidem: p. 7), se realiza no "homem futuro (...), imbuído por uma rebelião contra a existência humana tal como ela tem sido dada". Essa é a "questão política de primeira grandeza" (Ibidem: p. 3). Ao nos mantermos presos a uma filosofia política do discursivo e da ação na esfera pública, regulada pelos artefatos institucionais de estabilização dos conflitos, "pode suceder que nós, que somos criaturas ligadas à Terra e nos puse-

\footnotetext{
${ }^{5} \mathrm{No}$ "Prólogo" de A condição humana, ao falar sobre um objeto artificial a transformar a existência do ser humano, Hannah Arendt se refere ao primeiro artefato lançado ao espaço, o Sputinik: "em 1957, um objeto terrestre, feito pelo homem, foi lançado ao universo, onde durante algumas semanas girou em torno da Terra segundo as mesmas leis de gravitação que fazem girar e mantêm em movimento os corpos celestes o Sol, a Lua e as estrelas" (2010, p.1). O Sputinik I, durante 22 dias, do lançamento até que suas baterias se esgotassem, emitiu para a Terra um sinal "beep" que podia ser captado por rádio amador. Em meio à Guerra Fria, o satélite soviético causou grande impacto no cenário ideológico, econômico e militar, impulsionando diretamente a chamada "corrida espacial" com a disputa entre União Soviética e Estados Unidos. Para Arendt, contudo, um dos maiores impactos foi o filosófico existencial, pois se constatava que, através da tecnologia, "a humanidade não permanecerá para sempre presa à Terra" ou à sua velha condição humana, evidenciando aquilo que ficara desde sempre "relegado ao reino da literatura de ficção científica" (2010, p. 2).

${ }^{6}$ Cf. artigo de minha autoria: TELES, E. "Governamentalidade algorítmica e as subjetivações rarefeitas". Esse artigo problematiza a racionalidade de governo gerida pelos algoritmos. Argumenta-se que a governamentalidade, tal como definida por Michel Foucault, a saber, uma lógica de cálculos e estatísticas utilizada para conduzir a ação dos indivíduos, mesclada às funções das máquinas autônomas, configura um novo regime de produção de subjetividades. Estruturando as relações entre o humano e a máquina em velocidade instantânea e acessando o máximo de informações sobre os interesses e necessidades dos indivíduos, a governamentalidade algorítmica trabalha com a ideia de uma normatividade imanente ao próprio deslocamento e circulação dos dados, bloqueando experiências sociais e políticas com a eliminação das esferas de debates e de criação do comum.
} 
mos a agir como se fôssemos habitantes do universo, jamais sejamos capazes de compreender, isto é, de pensar e de falar sobre as coisas que, no entanto, somos capazes de fazer" (Ibidem: p. 4).

O lugar habitado, este "outro planeta" que transbordou irremediavelmente os limites da tradição, aparece como uma localização indistinta entre o humano e o artificial na qual essas categorias só podem ser abordadas enquanto classificações teóricas. A experimentação das novas localizações do político informa que:

As coisas e os homens constituem o ambiente de cada uma das atividades humanas, que não teriam sentido sem tal localização; e, no entanto, esse ambiente, o mundo no qual nascemos, não existiria sem a atividade humana que o produziu, como no caso de coisas fabricadas; que dele cuida, como no caso das terras de cultivo; ou que o estabeleceu por meio da organização, como no caso do corpo político (Ibidem, p. 26).

O contemporâneo turvou as distinções entre o público e o privado, as coisas e o humano, o sujeito e o objeto. Assim, sem as clássicas compreensões sobre a política, o discursivo, a participação cidadã e a representação se desvalorizam em meio às fronteiras indistintas do que antes se pensava ser sua localização. "A ascensão da administração, de suas atividades, seus problemas e dispositivos organizacionais" alterou o significado e a importância da separação de espaços próprios para determinadas atividades humanas, "ao ponto de torna-los quase irreconhecíveis" (Ibidem, p. 46).

Concebe-se que, ao invés de agir com os demais, os indivíduos se comportam de acordo com uma "moderna ciência da economia", enquanto "instrumento técnico" de governo das relações sociais (Ibidem, p. 51). Ainda que para Arendt as "leis da estatística" controlem apenas dados de grandes e longos eventos, o que deixaria escapar os acontecimentos originados na ação dos singulares, veremos com outros autores que certa revolução tecnológica e política transbordou esses limites. O modo arendtiano de lidar com o controle exercido pelos cálculos de governo é a valorização das "ocorrências raras da vida cotidiana". Afinal, dizia Arendt, seria "inútil buscar o significado da política" sem considerar os eventos específicos e as ações comuns (Ibidem: p. 52).

\section{O "desvio" no projeto político da mo- dernidade}

Seguindo à tradição moderna das teorias políticas, Jacques Rancière expôs a síntese de um agir com ênfase no discursivo. Para ele, seria preciso se observar três aspectos na política: primeiro, 
é necessário haver uma esfera de aparência do povo7, um "campo da experiência, de um visível que modifica o regime do visível"; segundo, o povo da aparência não pertence à unidade de grupos determinados, pois "a democracia é a instituição de sujeitos que não coincidem com partes do Estado ou da sociedade", o sujeito não-identitário; e, terceiro, o palco no qual o povo se exibe é o lugar do conflito social, não entre partes, mas um litígio que põe em jogo a própria situação de conflito (1996, pp. 102-103). Nessa definição da política, apenas o "visível" e seus sujeitos interagem por entre os objetos de suporte à ação (Estado, leis, esfera pública, instituições) para, entre si, decidirem discursivamente sobre o desentendimento.

Apesar de partilhar, de modo semelhante a Rancière, da leitura tradicional, Hannah Arendt desenvolveu uma crítica na qual a política teria perdido o seu sentido. A relação direta entre ação e fala teria se tornado inoperante, ou diminuído em importância, pois hoje habitamos "um mundo no qual as palavras perderam o seu poder" (Arendt, 2010 , p. 12). Talvez pudéssemos estender a percepção crítica arendtiana, pois se vivemos uma indistinção entre o público e o privado, efetivando-se um pro- blema na localização da política, como falar em um povo? Sobre o que o entendimento na esfera pública iria operar?

A vida sem o discurso "deixa de ser uma vida humana" (Ibidem: p. 221), fazendo da política a efetivação de uma utilidade, um meio para se atingir um fim. Lembra a autora que alguns dos significados da palavra "agir", que designa a atividade política, vem do grego "archein" e "prattein" (a primeira significando "começar", "conduzir", "governar" e, a segunda, "realizar", "acabar"). $\mathrm{Na}$ política em que o discurso perde em importância tem-se apenas como sujeito político "robôs executores a realizar coisas" (Ibidem: p. 223). Arendt compreendia que o discurso, apesar de muito útil como elemento de comunicação e informação, "poderia ser substituído por uma linguagem de signos" operada por processos automatizados (Ibidem: p. 224).

\footnotetext{
${ }^{7}$ Jacques Rancière problematiza a figura "povo" ao expor a dependência dessa categoria em relação às instituições de Estado: “Que existe uma entidade chamada povo que é a fonte do poder e o interlocutor prioritário do discurso político, é o que afirmam as nossas constituições e é a convicção que os oradores republicanos e socialistas de outrora desenvolveram sem titubear. (...) Pois 'o povo' não existe. O que existe são várias figuras de povo, mesmo antagônicas, figuras construídas favorecendo certos modos de reunião, certos traços distintivos, certas capacidades ou deficiências: povo étnico definido pela comunidade da terra ou do sangue; povo-rebanho vigiado pelos bons pastores; povo democrático implementando a competência de quem não tem qualquer competência particular; povo que ignora que os oligarcas mantêm distância etc." (2013, pp. 138-139).
} 
circundada pelo mundo e está em permanente contato com ele; a ação e o discurso são circundados pela teia de atos e palavras de outros homens, e estão em permanente contato com ela (Ibidem: p. 235).

Para a filósofa alemã o mundo atual se caracteriza pela perda da experiência na medida em que as ações e os pensamentos configuram-se como um "cálculo de consequências", uma espécie de "função do cérebro". "A ação logo passou a ser, e ainda é, concebida em termos de produzir e de fabricar", lançando o humano em "um funcionamento puramente automático, (...) entorpecido e 'tranquilizado' de comportamento" (Ibidem: pp. 402-403). Como em uma narrativa de ficção científica, Arendt imagina a cena em que os indivíduos, em um processo de fabricação, perdem sua condição de serem fundamentalmente separados das coisas, naturais ou artificiais 8 , e “(...) os corpos humanos começam gradualmente a ser revestidos por uma carapaça de aço" (Ibidem: p. 404).

A ação logo passou a ser, e ainda é, concebida em termos de pro- duzir e de fabricar, exceto que o produzir, dada a sua mundanidade e inerente indiferença à vida, era agora visto como apenas uma outra forma de trabalho, como uma função mais complicada, mas não mais misteriosa, do processo vital (Ibidem: p. 402).

A fabricação arendtiana é determinada por um duplo sentido de finalidade: por um lado, o fazer do homo faber segue a um projeto específico e previamente definido e, por outro, é uma atividade que se encerra quando o resultado final é atingido. Assim, a atividade do homo faber "chega a um fim com seu produto final, que não só sobrevive à atividade de fabricação como daí em diante tem uma espécie de 'vida' própria” (Arendt, 1997, p. 91). Tal percurso próprio, automático, revestido pelo fabricar de um processo previamente conhecido pelo especialista, caracterizariam as funções e estratégias de uma ação política contemporânea?

A indistinção entre o humano e o fabricado, mas também, entre o artificial e o natural, o sujeito e o objeto, a cultura e a natureza transformariam irremediavelmente o cenário político e de governo. Arendt, apesar de parti-

\footnotetext{
${ }^{8}$ Segundo Donna Haraway, "a ficção científica contemporânea está cheia de ciborgues - criaturas que são simultaneamente animal e máquina, que habitam mundos que são, de forma ambígua, tanto naturais quanto fabricados" (2009, p. 36). Identifica-se uma filosofia contemporânea, da qual Arendt teria sido uma das precursoras, que compreende certa maquinicidade ou a hibridização da política.

${ }^{9}$ No livro Ação política em Hannah Arendt refleti sobre a crítica arendtiana à política contemporânea a partir das experiências totalitárias do século XX (Teles, 2019).
} 
lhar da percepção de uma política fabricada, ainda considerou em sua obra a esperança de que ações políticas e não políticas pudessem manter suas distinções tradicionais. Em vários momentos de suas reflexões ela sustentou a inviabilidade da "esperança utópica de que seja possível tratar os homens como se tratam outros 'materiais' " (2010, p. 236). A autora estabelece limites entre formas do agir, bem como entre objeto e sujeito. Entretanto, ela mesma anuncia a impossibilidade de limitar os modos da existência política, seja qual for a atividade: "a ilimitabilidade da ação é apenas o outro lado de sua tremenda capacidade de estabelecer relações" (Ibidem: p. 239).

A divisão da filosofia moderna entre aquilo que é por natureza e o que é por fabricação do humano se desfaz. Ambas atividades movimentam os híbridos, aqueles que são quase humanos e, ao mesmo tempo, quase objetos, levando a política além do meramente discursivo.

Segundo Bruno Latour:

(...) talvez o quadro moderno houvesse conseguido se manter por mais algum tempo caso seu próprio desenvolvimento não houvesse estabelecido um curto-circuito entre a natureza, de um lado, e as massas humanas, de outro. Enquanto a na- tureza permaneceu longínqua e dominada, ainda se parecia vagamente com o polo constitucional da tradição. Parecia reservada, transcendental, inesgotável, longínqua. Mas como classificar o buraco de ozônio, o aquecimento global do planeta? Onde colocar estes híbridos? Eles são humanos? Sim, humanos pois são nossa obra. São naturais? Sim, naturais porque não foram feitos por nós. São locais ou globais? Os dois. As massas humanas que as virtudes e os vícios da medicina e da economia multiplicaram também não são fáceis de mapear. Em que mundo abrigar estas multidões? Estamos no campo da biologia, da sociologia, da história natural, da sociobiologia? É nossa obra, e no entanto as leis da demografia e da economia nos ultrapassam infinitamente. A bomba demográfica é global ou local? Os dois. Portanto, tanto do lado da natureza quanto do lado do social, não podemos mais reconhecer as duas garantias constitucionais dos modernos: as leis universais das coisas, os direitos imprescritíveis dos sujeitos (2013, p. 54).

\footnotetext{
${ }^{10}$ Para Hannah Arendt, a era moderna “começou no século XVII, terminou no limiar do século XX” (2010, p. 7) e caracterizou-se
} 
A “era moderna"10, segundo Hannah Arendt, é marcada pela valorização das ferramentas e dos instrumentos. As revoluções nas formas de vida provêm do impacto da fabricação, o encontro da "parafernália de instrumentos" em conexão com as "capacidades produtivas do homem" (2010, p. 369). Os modernos seguiram e alimentaram a ideia de que o homem poderia conhecer aquilo que ele mesmo faz. Este novo olhar para o conhecimento fez com que ocorresse a troca das questões na história da ciência do "o quê" ou "por quê" para o "como" algo existe. O experimento seria o processo no qual se poderia obter a resposta ao "como" fazer algo e produzir determinado efeito. A partir desse ponto, agir e conhecer passou a ser um ato de produção e fabricação. $O$ foco do conhecimento saiu das coisas universais e priorizou a história dos processos, pois se "sabia que um processo de produção precede necessariamente a existência efetiva de todo objeto" (Ibidem: p. 371).

A imensa dificuldade em manter a política dentro de bordas delimitadas se traduz na sua imprevisibilidade. Dela não se antecipa o que ocorrerá "pois se assim fosse um computador eletrônico seria capaz de predizer o fu- turo", mas também a imprevisibilidade dos efeitos de seus resultados (Ibidem: p. 239). A ação é imprevisível, pois resulta das relações entre sujeitos singulares e discursos dissonantes e, por mais que se criem modos de estabilizar as profundas diferenças - como, por exemplo, as leis -, não se poderia predizer o ato (Ibidem: 248-59). Justamente por essa característica certa política fabricada ou das máquinas políticas cresce em importância no contemporâneo. Em busca de predizer os atos, processos e artefatos acionados são uma série de mecanismos de governo para conduzir as etapas da ação e estabelecer estratégias de controle ${ }^{11}$.

\section{A ação e o esvaziamento da cidadania}

Do ponto de vista da valorização de uma política mecânica e tecnológica, em detrimento da esfera pública do discursivo, persuasivo e dialógico, a consideração do experimento, do saber sobre o "como" e do domínio processual têm resultado na instrumentalização da realidade para se atingir determinados objetivos. Considerando ainda que a ação política tem como função principal, se-

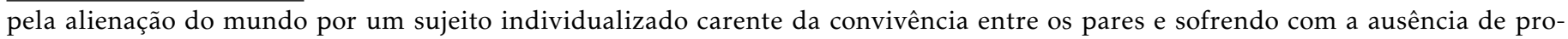
fundidade no pensamento. Do ponto de vista da temática desse artigo o que nos interessa é o momento político e filosófico no qual estratégicas mecânicas e funcionais ganham relevância nas relações de poder.

${ }^{11}$ É o caso da eleição presidencial norte americana de 2016, na qual a empresa de marketing político Cambridge Analytica usou de dados de milhões de usuários da rede social Facebook para conduzir eleitores a votarem em Donald Trump, que viria a se tornar presidente. Produz-se uma política preditiva determinando decisões com base nos processos autômatos e eliminando em grande medida uma característica fundamental da ação política, o "risco" de sua imprevisibilidade. Cf. "Presidente da Cambridge Analytica confessa influência em eleições nos EUA", in: O Estado de S. Paulo, de 21 de março de 2018, p. 18.
} 
gundo certa filosofia política ${ }^{12}$, a condução dos indivíduos, inclusive para que a imprevisibilidade dos eventos tenha seus efeitos contornados, os artefatos e a fabricação passaram a atuar fundamentalmente sobre a vida e os corpos.

Seria "como se a vida individual" tivesse um "funcionamento puramente automático", "submersa no processo vital global" (Arendt 2010: 403). Abandonada a um modelo "funcional, entorpecido e 'tranquilizado' de comportamento" (Ibidem: p. 403), a individualidade deixaria de ser uma unidade singular de potencialidades da ação para se tornar apenas saídas e entradas de dados e reações nos processos geridos pelas tecnologias. Não seria o fim do indivíduo, porém, a anulação dos sujeitos congelados em bolhas cada vez mais controladas e limitadas.

O indivíduo na condição de átomo, na qual "cada partícula tem, aparentemente, a 'liberdade' de comportar-se como quiser" (Ibidem: p. 404), dissolvese na massa de elementos que se comportam como uma multidão. O colapso do Estado-nação e as consequências da Primeira Guerra Mundial criaram as condições para desfazer as características tradicionais de sociabilidade e cidadania na Europa. As massas de apátridas produzidas se definiam pelo grande volume, pela indiferença polí- tica e encontravam-se atomizadas socialmente.

O termo massa só se aplica quando lidamos com pessoas que, simplesmente devido ao seu número, ou à sua indiferença, ou a uma mistura de ambos, não se podem integrar numa organização baseada no interesse comum, seja partido político, organização profissional ou sindicato de trabalhadores. Potencialmente, as massas existem em qualquer país e constituem a maioria das pessoas neutras e politicamente indiferentes, que nunca se filiam a um partido e raramente exercem o poder de voto (Arendt, 1989 , p. 361).

O princípio da igualdade presente no ordenamento de qualquer Estadonação entrou em colapso. Desse modo, o totalitarismo destruiu as redes sociais de comunicação e as esferas públicas visando mobilizar as massas despolitizadas. A desvalorização da experiência comum foi um processo que continuou nas democracias do pós-guerra, ainda que institucionalmente as estruturas fossem outras e discursivamente se reconhecesse as estratégias autoritá-

\footnotetext{
${ }^{12}$ A referência para um poder politico que exerce a condução, ou o pastoreio, das populações (corpo coletivo) pode ser lida em Michel Foucault, no seminário Segurança, Território, População (2008), aula de 08 de março de 1978: "Da pastoral das almas ao governo político dos homens".
} 
rias. A atividade política, quanto mais instrumentalizada e mecanizada se tornou, mais foi se limitando à ação de poucos. Os especialistas nos processos de governo substituíram as possibilidades do agir imprevisível e inovador fruto da reunião plural das singularidades.

Em uma política fabricada, a ação e o discurso são considerados mais pela efetividade de seu uso e efeitos do que pelo conteúdo discursivo. Nesse contexto, o fundamento da ação política é a "noção de que os homens só podem viver juntos, de maneira legítima e política, quando alguns têm o direito de comandar e os demais são forçados a obedecer" (Arendt, 2010, p. 277). Portanto, o problema a ser tratado é o modo de governo, a eficácia e o controle que pode exercer. Pode-se observar que a democracia representativa, de certo modo, sintetizou o controle da capacidade política dos sujeitos em termos como "participação" e "cidadania", esvaziados na medida em que não vão além de uma esfera pública e de uma política discursiva com sérios limites. "Seria necessário uma outra democracia? Uma democracia estendida às coisas?" (Latour, 2013, p. 17).
Como pensar em uma política que transborde os limites da representação? Uma ação cujo funcionamento extrapole os significados expressos pelos discursos? Qual a profundidade do mundo fabricado, artificial, sem o poder exclusivo das palavras? Faria sentido perguntarmos pelo sujeito da política diante de uma ação definida por meio de dispositivos com funções de controle?

\section{Arquiteturas e técnicas políticas}

Quando Michel Foucault se refere a uma "microfísica do poder" 13 ele expõe o deslocamento em relação a toda uma política representacional e discursiva. O tipo de intervenção sobre o humano e o ambiente em que este habita, sobre o corpo individual ou coletivo, definese por funções diferentes e, ao mesmo tempo, complementares, que remetem à reflexão sobre um agir político compreendido através dos efeitos que produz.

As técnicas que incidem sobre o corpo visam aprimorá-lo para que exerça melhor sua função produtiva nas relações de poder. Objetiva-se fabricar um corpo a ser utilizado em suas pos-

\footnotetext{
${ }^{13} \mathrm{O}$ diagnóstico sobre a existência de uma microfísica do poder visa desmontar a ideia universal de identificação entre poder e Estado ao considerar toda uma rede de poderes entre as micro-relações, por toda parte, dentro ou fora das instituições. Aponta ainda para o fato de os poderes agirem não só por meios repressivos, mas também disciplinares e reguladores. Para saber mais sobre as micro-relações de poder há a publicação brasileira com coletânea de ensaios sobre o tema no livro Microfísica do poder (Foucault, 1979).

${ }^{14}$ Um bom exemplo de visão da política como um poder produtivista, a partir de gestões da vida e do corpo por parte de instituições, se encontra na entrevista do general Eduardo Villas Bôas, comandante do Exército durante os governos dos presidentes Dilma Roussef ( $2^{\circ}$ mandato) e Michel Temer. Perguntado sobre como resolver a questão da violência urbana, o destacado militar respondeu: "Somos um país carente de disciplina social, que prioriza os direitos individuais em relação ao coletivo e ao interesse social.
} 
sibilidades máximas, produzindo mais, melhor e por mais tempo ${ }^{14}$. E, ao reproduzir funções e mecanismos políticos, diminuir a potência de revolta e de resistência, neutralizando sua capacidade de se indispor à ordem (Foucault, 2009).

Em período semelhante ao que Arendt nomeou por "era moderna" (algo que se inicia entre os séculos XVII e XVIII), Michel Foucault identificou o surgimento de técnicas visando à fabricação de soldados por meio de máquinas de adestramento do corpo. Através de "automatismos do hábito" (Ibidem: p. 131) se descobre o corpo como suporte e alvo das relações de poder. A noção central mobilizada por estas técnicas é a de "docilidade": "é dócil um corpo que pode ser submetido, que pode ser utilizado, que pode ser transformado e aperfeiçoado" (Ibidem: p. 132).

As disciplinas desmembram, reduzem as forças dos grandes blocos, reordenam e fabricam indivíduos. Suas técnicas tomam "os indivíduos ao mesmo tempo como objetos e como instrumentos de seu exercício" (Ibidem: p. 164). A singularização das unidades mínimas em torno do indivíduo é um modo de melhor aplicar, em seus ínfimos detalhes, as técnicas de adestramento do corpo. Contudo, a estratégia visa à mul- tiplicação através de novas conexões, utilizando os corpos enquanto um todo. Trata-se de uma técnica econômica, com cada passo permanentemente calculado em minúcias.

Dispositivo importante, pois automatiza e desindividualiza o poder. Este tem seu princípio não tanto numa pessoa quanto numa certa distribuição concertada dos corpos, das superfícies, das luzes, dos olhares: numa aparelhagem cujos mecanismos internos produzem a relação na qual se encontram presos os indivíduos. As cerimônias, os rituais, as marcas pelas quais se manifesta no soberano o mais-poder são inúteis. Há uma maquinaria que assegura dissimetria, o desequilíbrio, a diferença. Pouco importa, consequentemente, quem exerce o poder. (...) É uma máquina maravilhosa que, a partir dos desejos mais diversos, fabrica efeitos homogêneos de poder (Ibidem: pp. 191-192).

A economia funcional e contínua, a partir dos próprios corpos singulares e suas multiplicidades, ainda que se in-

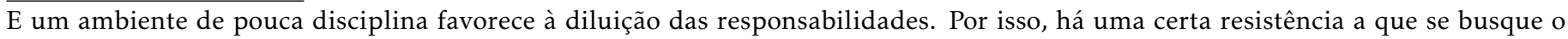
saneamento das condutas individuais e coletivas. Por outro lado, estamos vivendo uma imposição do politicamente correto, vivendo uma verdadeira ditadura do relativismo e com uma tendência a que não se estabeleçam limites nas condutas. (...) Quando nós vemos agressões a mulheres, abusos, quando vemos desrespeito, na raiz disso está a falta de limite e de disciplina que existe na sociedade". In: "Contaminação de tropas federais por facções criminosas preocupa", in: O Estado de S. Paulo, de 15 de janeiro de 2018 , p. 12.
} 
sira em uma hierarquia, leva os dispositivos disciplinares a operarem não só de cima para baixo, mas também em sentido inverso, bem como lateralmente e transversalmente: "organiza-se assim como um poder múltiplo, automático e anônimo" (Ibidem: p. 170). As disciplinas funcionam por movimentações e atos relacionais que se sustentam em seus próprios mecanismos, desinvestindo as ações políticas da persuasão discursiva e das oposições binárias ideológicas.

Sua espacialidade não se define por um território ou local específico. “(...) O lugar que alguém ocupa numa classificação, o ponto em que se cruzam uma linha e uma coluna, o intervalo numa série de intervalos que se pode percorrer sucessivamente" (Ibidem: pp. 140141). São os processos e o adestramento operacional que importam, as "disciplinas" fazem com que os corpos sejam distribuídos e circulem em uma rede de acordo com as demandas de produção e dominação'

\section{Tecnologias de governo da vida}

No século XX, houve uma apropriação do biológico pela institucionalização do Estado realizada pelos regimes totalitários. Tais regimes eliminaram não só a esfera pública, mas também qualquer possibilidade de espontaneidade humana, interferindo nas atividades essenciais à existência. Para tanto destruíram as teias sociais de comunicação e convivência e mobilizaram as massas despolitizadas, as quais se definiam pelo volume grande de pessoas, pela apatia e indiferença política, se encontrando atomizadas socialmente (Arendt, 1989).

Ao totalitarismo não bastava a eliminação dos opositores, mas havia a necessidade da posse de todo o tecido social, impondo o controle absoluto e incondicional. $\mathrm{O}$ novo regime colocou em questão os conceitos tradicionais de poder político ao apresentar uma concepção sem precedentes de dominação, expondo os limites das instituições políticas em manterem a estabilidade dos direitos e das leis. Com a experiência dos campos de concentração, na qual os indivíduos se encontravam reduzidos a

\footnotetext{
${ }^{15}$ É interessante o exemplo do tempo gasto no trânsito, o que inclui espera em ponto de ônibus, circulação e transferências entre tipos de transportes. Cada corpo paulistano, por exemplo, usuário do transporte público, chega a despender 45 dias por ano, em média, na circulação urbana. Seria difícil imaginar que um indivíduo, ou sua multiplicidade (o que é exponencialmente mais potente), pudesse prodigalizar tanto tempo diário com circulação entre trabalho, estudo (seu ou de seus filhos) e casa, se não fossem seus corpos altamente adestrados, dóceis e submissos. O próprio transporte, seus objetos e indivíduos, é a instituição disciplinar e as relações por ele e nele produzidas são a ação política de controle. Talvez pudéssemos levantar a hipótese de que a quantidade massiva de ônibus queimados nas periferias das grandes cidades (em São Paulo, no ano de 2014, foram mais de 200 veículos incendiados) se deva, ao menos em parte, ao grau abusivo e excessivo de uso da docilidade dos corpos para bloquear revoltas contra a baixa qualidade dos serviços públicos na cidade. Cf. "Pesquisa sobre mobilidade urbana", feito pela Rede Nossa São Paulo, publicada em setembro de 2016. Disponível em http://www.mobilize.org.br/midias/pesquisas/mobilidade-urbana-e-transporte-publico-em-sp.pdf. acesso em setembro de 2020.
} 
simples seres viventes, Arendt refletiu sobre a substituição da política tradicional por uma política do biológico. A ação instrumentalizada para o controle da vida virou uma função sem sujeito, cujas relações entre as pessoas, e destas com as coisas e vice-versa, ocorreria por meio de mecanismos próprios para lidar com a gestão de processo produtivos.

Já para Michel Foucault, um poder sobre o biológico surge antes das experiências do século XX e por estas é reforçado ${ }^{16}$. As populações se tornam alvo de distribuições a partir do fato de serem grupos de corpos biologicamente (in)animados. Se o poder disciplinar localizava, examinava e distribuía os indivíduos entre vivos, mortos e doentes, um novo poder, a biopolítica, conduzia as populações para mais viverem ou para a morte, a partir da ideia central de que a vida (e os corpos) é a grande ferramenta política.

Parece-nos que um dos fenômenos fundamentais do século XIX foi, é o que se poderia denominar a assunção da vida pelo poder: se vocês preferirem, uma tomada de poder sobre homem enquanto ser vivo, uma espécie de estatização do biológico ou, pelo menos, uma certa inclinação que conduz ao que se poderia chamar de estatização do biológico (Foucault, 1999, pp. 285-286).

Com a tecnologia biopolítica aparece um novo personagem, a população, e com ela os fenômenos relacionados, como: natalidade, mortalidade, longevidade, enchente, saúde pública, circulação nas cidades etc. Os novos mecanismos se dedicarão às estatísticas, às previsões e às medições. "Trata-se sobretudo de estabelecer mecanismos reguladores que, nessa população global com seu campo aleatório, vão poder fixar um equilíbrio, manter uma média" (Ibidem, p. 293). Na biopolítica, as tecnologias de governo dos corpos e da vida centralizarão suas ações nos acontecimentos eventuais procurando intervir sobre eles antes que se concretizem.

Para Hannah Arendt, como para outros pensadores, a ação é imprevisível, pois resulta da relação social entre sujeitos singulares e discursos dissonantes e, por mais que se criem modos de estabilizar as profundas diferenças - como, por exemplo, as leis -, não se poderia predizer totalmente o ato (2010, pp. 303-308).

\footnotetext{
${ }^{16}$ No seminário Em defesa da sociedade, Michel Foucault argumenta sobre o impacto da experiência da "sociedade nazista" na absolutização do biopoder: "Tem-se, pois, na sociedade nazista, esta coisa, apesar de tudo, extraordinária: é uma sociedade que generalizou absolutamente o biopoder, mas que generalizou, ao mesmo tempo, o direito soberano de matar. Os dois mecanismos, o clássico, arcaico, que dava ao Estado direito de vida e de morte sobre seus cidadãos, e o novo mecanismo organizado em torno da disciplina, da regulamentação, em suma, o novo mecanismo de biopoder, vêm, exatamente, a coincidir" (1999: p. 311).
} 
Diante da imprevisibilidade da ação e das formas biopolíticas de condução das populações teremos duas implicações: será preciso obter cada vez mais dados sobre os acontecimentos procurando antecipá-los; e, obrigará uma ação que vincule as tecnologias de governo com as técnicas disciplinares e os mecanismos da soberania, os quais agem no controle ou na repressão preventiva.

A economia de governo, na passagem do século XVIII para o XIX, segundo Foucault, buscou criar dispositivos que agissem sobre o fenômeno, mas sem alterá-lo, danificá-lo ou eliminá-lo. A estratégia seria fazer uso dos acontecimentos, aproveitando a sua realidade e em conexão com várias outras realidades, de modo a gradativamente compreendê-lo, exercendo certo freio, controle e, ao fim, podendo mesmo eliminá-lo. Conectado à realidade do evento os dispositivos de governo vão cada vez mais se utilizar dessas oscilações do fenômeno sem tentar previamente impedi-lo. Na normatização da biopolítica trata-se de:

(...) inserir o fenômeno em questão (...) numa série de acontecimentos prováveis. Em segundo lugar, as reações do poder ante esse fenômeno vão ser inseridas num cálculo que é um cálculo de custo. Enfim, em terceiro lugar, em vez de instaurar uma divisão binária
(...), vai-se fixar de um lado uma média considerada ótima e, depois, estabelecer os limites do aceitável, além dos quais a coisa não deve ir. É portanto toda uma outra distribuição das coisas e dos mecanismos que assim se esboça (Foucault, 2008, p. 9).

Não há déficit, desvio ou falha. Há processos, meios e circulações a serem conduzidos. A compreensão da ação política a partir das técnicas e tecnologias de controle dos espaços e de suas circulações possibilita à filosofia política aprofundar as análises das relações de poder enquanto funções e mecanismos de controle. Bem como estratégias de poder se efetivando entre o biológico e o social, o discursivo e o mecânico, nos permite identificar em Foucault uma ação política híbrida cuja potência reside justamente na intersecção entre essas diferentes e complementares formas de controle, gestão e condução da vida. Afinal, "o corpo é o lugar de uma justaposição, de uma sucessão, de uma mistura de espécies diferentes" (Foucault, p. 9). Os corpos, suas subjetivações e suas ações são tanto biológicas, quanto culturais, assim como mecânicas e automatizadas.

\section{A gestão maquínica das subjetivações}

No livro Mil platôs, ao comentar sobre as técnicas fascistas de atuação, Gil- 
les Deleuze e Félix Guattari explicam como máquinas de guerra micropolíticas agem sobre o desejo de modo a tornar o fascismo um movimento de massa, potente e catastrófico. É através de micro organizações, fluxos se deslocando por entre segmentos mais estáveis. "Mas o desejo nunca é separável de agenciamentos complexos que passam necessariamente por níveis moleculares, microformações que moldam de antemão as posturas, as atitudes, as percepções, as antecipações, as semióticas, etc."; os desejos resultam, mais do que de energias pulsionais, de "um engineering de altas interações" (Deleuze e Guattari, 2012b, p. 101).

Tornamo-nos dispositivos aplicáveis de uma estrutura arquitetada a partir de redes, um modo de governo proveniente do capitalismo pós-industrial e capaz de lidar com as subjetividades em suas formas mais capilares. As máquinas de guerra políticas, potências da sociedade de controle, atuam em um âmbito molar ${ }^{17}$, o das instituições e dos grandes centralismos (notadamente o Estado), e, através de fluxos moleculares, atomizados, conduzidos massiva- mente por pequenas engenharias de governo dos desejos. As máquinas transformam a ação em cifras calculáveis e modulam a condução dos corpos por meio de códigos informacionais cujas combinações infinitas permitem certa previsibilidade e o ilimitado de uma política tecnocientífica. Quanto mais central e maior forem os dispositivos de segurança, maior será a microgestão dos pequenos medos e das desesperanças fluidas. Imperceptíveis ao olhar são, contudo, tão evidentes quanto o cheiro de algo podre do qual desconhecemos a proveniência.

Bom exemplo é a expectativa positiva de que uma intervenção militar na gestão da segurança pública, no estado do Rio de Janeiro, resolveria por meio da violência, legal, a violência urbana crescente $\mathrm{e}^{18}$. Em um jogo de movimentações molares e moleculares, entre, por um lado, articulações institucionais que vêm desde as Unidades de Polícia Pacificadora (UPPs) e os grandes eventos esportivos, e, de outro, imagens de televisão com arrastões e saques na Zona Sul da cidade, se produziu um clamor conservador, pois demandante do uso

\footnotetext{
${ }^{17}$ Gilles Deleuze e Félix Guattari desenvolveram os conceitos de molar e molecular. Molar se refere ao campo dos controles e das representações e são gestados, normalmente, pelas instituições centralizadoras, como as do Estado. O molecular é a expressão dos devires e dos desejos, por onde os fluxos se relacionam por meio de inúmeras conexões. “(...) A política e seus julgamentos são sempre molares, mas é o molecular, com suas apreciações, que a 'faz' ” (Deleuze e Guattari, 2012b, p. 112). Um e outro campo podem existir conjuntamente, "um grupo de trabalho comunitário pode ter uma ação nitidamente emancipadora a nível molar, mas a nível molecular ter toda uma série de mecanismos de liderança falocrática, reacionária, etc. Isso, por exemplo, pode ocorrer com a igreja. Ou, o inverso: ela pode se mostrar reacionária, conservadora, a nível das estruturas visíveis de representação social, a nível do discurso tal como ele se articula no plano político, religioso, etc., ou seja, a nível molar. E, ao mesmo tempo a nível molecular, podem aparecer componentes de expressão de desejo, de expressão de singularidade, que não conduzem, de maneira alguma, a uma política reacionária e de conformismo" (Guattari e Rolnik, 1999, p. 133).

${ }^{18}$ Comentei o acontecimento "intervenção" no artigo "A revolta dos tuiutis", publicado em https://www.peixe-eletrico.com/singlepost/2018/02/23/A-revolta-dos-Tuiutis, acesso em setembro de 2020.
} 
de mais violência. A efetivação da "intervenção" passa ao largo das principais elaborações de propostas de políticas de segurança pública por parte de especialistas e pesquisadores 19 . Produz-se o medo e a desesperança, bem como as demandas e os desejos, de tal modo que a "fórmula dos ministérios do interior poderia ser: uma macropolítica da sociedade para e por uma micropolítica da insegurança" (Deleuze e Guattari, 2012b, p. 102).

\begin{abstract}
A política opera por macrodecisões e escolhas binárias, interesses binarizados; mas o domínio do decidível permanece estreito. E a decisão política mergulha necessariamente num mundo de microdeterminações, atrações e desejos, que ela deve pressentir ou avaliar de um outro modo. (...) Boa ou má, a política e seus julgamentos são sempre molares, mas é o molecular, com suas apreciações, que a "faz" (Ibidem: pp. 111-112).
\end{abstract}

As máquinas políticas não se constituem somente como um espaço de técnicas e peças fabricadas para comporem suas engrenagens e sistemas. São, sobretudo, compostas de fluxos e multiplicidades de forças dotadas da potên- cia de agenciamento de seus deslocamentos, territórios e elementos. Ao invés de enfatizar os sujeitos, seus discursos, os espaços estáveis e previamente definidos, os agenciamentos maquínicos privilegiam os processos, o "como" da ação política, as tecnologias e estratégias aplicadas. Seria justamente no mundo híbrido, no entre os "quasesujeitos" e os "quase-objetos" (Latour, 2013) que os agenciamentos de forças e fluxos se processam.

No Manifesto ciborgue, Donna Haraway desenvolve a ideia do ciborgue, "um organismo cibernético, um híbrido de máquina e organismo, uma criatura de realidade social e também uma criatura de ficção" (2009, p. 36). Aqui se assemelha aos processos maquínicos, dos encontros entre a política representativa e institucional e os desejos emergentes dos processos moleculares. Já Haraway se refere à realidade social como a fricção entre as experiências concretas com a ficção da transformação do mundo, uma efetiva construção política. "O ciborgue é nossa ontologia; ele determina nossa política" (Ibidem, p. 37). Se o enfoque deleuzo-guattariano está nos processos, para a filósofa o destaque é o caráter híbrido do "ciborgue". Ele não participa de qualquer narrativa sobre o momento "original", como os sujeitos universais das teorias políticas, e se constitui em um telos dos proces-

\footnotetext{
${ }^{19}$ Uma referência é a publicação "Rio sob intervenção: medo, percepção de risco e vitimização na cidade do Rio de Janeiro", de PAIVA et alli (2018), do Fórum Brasileiro de Segurança Pública (FBSP).
} 
sos contemporâneos de dominação, das subjetividades "libertas" e impressas no indivíduo usuário das tecnologias de satisfação do desejo e da segurança. Os corpos e as coisas passam a compor, ou ainda, a serem máquinas políticas de alta performance.

As potências do hibridismo abrem a política para outras possibilidades de experimentações criativas se forem expostas às estratégias maquínicas de sujeição e controle. Em seu interior, a ação híbrida, discursiva e, ao mesmo tempo, funcional, se compreendida em seus processos e mecanismos pode gerar uma explosão em dessubjetivações das novas formas de vida, ainda em condição de servidão e docilidade. Em um mundo ciborguiano pode ocorrer de as pessoas se apropriarem das afinidades ou da indistinção entre seres vivos e seres fabricados, de modo que "não temam identidades permanentemente parciais e posições contraditórias" (Ibidem, p. 46). Manifesta Donna Haraway:

A luta política consiste em ver a partir de ambas as perspectivas ao mesmo tempo, porque cada uma delas revela tanto dominações quanto possibilidades que seriam inimagináveis a partir do outro ponto de vista. Uma visão única produz ilusões piores do que uma visão dupla ou do que a visão de um monstro de múltiplas cabeças. As unidades ciborguianas são mons- truosas e ilegítimas: em nossas presentes circunstâncias políticas, dificilmente podemos esperar ter mitos mais potentes de resistência e reacoplamento (Ibidem: p. 46).

Os híbridos seriam relações, junções e desmembramentos de elementos heterogêneos, transformando as forças, impulsionando ou anulando seus fluxos, descodificando continuamente o que está posto. A transformação contínua se aplica a complexos tecnológicos, elaborações culturais ou de hábitos do cotidiano, assim como nos desejos e afetos dos indivíduos e nos regimes de produção de subjetividades. "Não há mais de uma parte a humanidade e de outra um sistema de objetos em relação aos quais os humanos se situariam como uma saliência" (Mbembe, 2020, p. 17, tradução nossa). Modificam-se regras, normas, códigos, ferramentas, equipamentos.

As articulações entre o orgânico e o inorgânico, os códigos e os meios, o molecular e o molar, a micropolítica e os equipamentos de Estado, o discursivo e o funcional se constituem nos fenômenos e acontecimentos da ação política. Mais do que uma ontologia, ou uma biosfera pública, discursiva e estável, se tem uma espécie de "mecanosfera” (Deleuze e Guattari, 2012a) na qual os elementos mecânicos e técnicos encontram-se em simbiose e aliança com o humano e o biológico. E não ape- 
nas como meios ou instrumentos, mas igualmente enquanto elementos do fazer político.

\section{Nem humanos, nem máquinas, mas estratégias e processos}

Segundo o argumento da tradição, ao propor a separação entre as coisas da natureza e as fabricadas, a política seria "os homens no plural, isto é, os homens na medida em que vivem, se movem e agem neste mundo, [e] só podem experimentar a significação porque podem falar uns com os outros e se fazer entender aos outros e a si mesmos" (Arendt 2010: 5). Já para Deleuze, as relações de poder operam por meio de diagramas de mecanismos e tecnologias, máquinas operando de modo autônomo a toda forma conteudística:

O diagrama não é mais o arquivo, auditivo ou visual, é o mapa, a cartografia, coextensiva a todo o campo social. É uma máquina abstrata. Definindo-se por meio de funções e matérias informes, ele ignora toda distinção de forma entre um conteúdo e uma expressão, entre uma formação discursiva e uma formação não- discursiva. É uma máquina quase muda e cega, embora seja ela que faça ver e falar (Deleuze 2006: 44).

Investe-se em uma economia do político enquanto fabricação, maquinismos, sujeitos ciborgues, hibridismo entre as antigas formas da política, da representação e dos discursos, e as novas, dos processos, da previsibilidade, dos artefatos e das técnicas. Intensificam-se as formas de uso das tecnologias e normas em proveito das máquinas políticas, sofisticando os regimes de subjetivações. Intensifica-se uma governança por meio de algoritmos, caracterizando "globalmente um certo tipo de racionalidade (a)normativa ou (a)política que repousa sobre a coleta, agregação e análise automatizada de dados em quantidade massiva de modo a modelizar, antecipar e afetar, por antecipação, os comportamentos possíveis" (Rouvroy e Berns, 2015, p. 42).

Há uma diluição do indivíduo em meio a uma cosmologia formada por dados, o que diminui em importância as formas discursivas de ação política. Através dos Big Data ${ }^{20}$ cada vez mais se desinveste na identificação do indivíduo. Os indivíduos tornam-se objetos da observação e da predição, enquanto as máquinas traduzem costumes, gostos

\footnotetext{
${ }^{20}$ O termo Big Data se refere a um grande armazenamento de dados em velocidade, variedade e volume incalculáveis. Sua potência está em que, através dos algoritmos, dele se pode extrair informações valiosas e eficientes sobre processos produtivos e, inclusive, medidas preditivas a partir de detalhadíssimas informações sobre comportamentos, coisas ou seres animados, inclusive humanos.
} 
e ações, gerando novos regimes de subjetivação, ou inda, a rarefação desses processos. Como nessa tradução não há neutralidade, deriva-se a racionalidade governamental com uma ação política fabricada para a qual a questão central passa a ser os processos, as tecnologias de controle e a condução dos corpos.

Se a tradição teórica tem pensado a política como o exercício dos discursos e gestos, quando ato e palavra singulares dos indivíduos ou grupos políticos buscam persuadir maiorias com o fito de transformar o futuro, certa filosofia contemporânea tem pensado a ação e as relações de poder via um processo híbrido, funcional e discursivo, no qual os mecanismos de controle têm uma amplitude e eficácia de relevância fundamental.

Agora somos atravessados por objetos, trabalhados por eles tanto quanto nós os trabalhamos. Há um devir-objeto da humanidade que é a contrapartida do devir-humano dos objetos. Nós somos o minério que nossos objetos são responsáveis por extrair. Eles agem conosco, nos fazem agir e, acima de tudo, nos inspiram (Mbembe, 2020,

\section{p. 17, tradução nossa).}

Sob a superfície de uma política discursiva, binária e das subjetividades individualizadas operam "fluxos descodificados" cujas funções advém da própria operacionalidade produtivista dos mecanismos e das máquinas políticas. Esses fluxos, diferentemente da visibilidade das esferas públicas do regime democrático, são eficientes "máquinas de ver" cuja eficácia se encontra em sua capacidade de produzir "modos de ser" (Bruno 2013). São fluxos subterrâneos, invisíveis nas esferas discursivas dos corpos do "povo" ou do "cidadão", mas que aparecem com evidência quando movem as placas tectônicas da sociedade de controle 21 .

$O$ fato de que em nossa sociedade se fala, se gesticula e se comunica não implica em um logocentrismo. Mas aponta para um mundo tecnológico e maquínico no qual a fala e o agir se tornam engrenagens eficazes dos modos de governo não pelo conteúdo, mas pela técnica de absorver as subjetividades individualizadas em meio aos mecanismos de poder. Trata-se de uma política caracterizada "pelo estreito entrelaçamento de várias figuras da razão: a razão econômica e instrumental, a ra-

\footnotetext{
${ }^{21}$ Aqui fazemos uma referência à crítica de Félix Guattari aos sujeitos universais e em favor da reflexão sobre os "componentes de subjetivação" sob a superfície, não evidentes: "O sujeito não é evidente: não basta pensar para ser, como o proclamava Descartes, já que inúmeras outras maneiras de existir se instauram fora da consciência, ao passo que o sujeito advém no momento em que o pensamento se obstina em apreender a si mesmo e se opõe a girar como um pião enlouquecido, sem enganchar em nada dos territórios reais da existência, os quais por sua vez derivam uns em relação aos outros, como placas tectônicas sob a superfície dos continentes. Ao invés de sujeito, talvez fosse melhor falar em componentes de subjetivação trabalhando, cada um, mais ou menos por conta própria" (1990: 17).
} 
zão eletrônica e biológica. Baseia-se na profunda convicção de que não há mais distinção entre seres vivos e máquinas" (Mbembe, 2020, p. 9, tradução nossa).

Máquinas, redes, objetos, estruturas, diagramas, tecnologias agem não somente por meio das objetividades que lhes são inerentes, mas possuem um regime de subjetivação, ou de dessubjetivação, pois procedem por sugestão, solicitação, bloqueio, anulação, incentivo, procedimento, cálculo. Digno de nota que Michel Foucault (2008) tenha apresentado a governamentalidade como a "ação de condução da ação do outro" por meio dos procedimentos técnicos semelhantes aos acima descritos. Se na política discursiva, o que mais a caracteriza seja o molde sobre o qual os sujeitos universais serão representados, na política mecânica e tecnológica se destaca a modelagem e a dimensão do processo produtivo de subjetivação empreendido pelas máquinas políticas.

\section{Referências}

ARENDT, Hannah. A condição humana. Tradução Roberto Raposo. Revisão técnica e Apresentação Adriano Correia. Rio de Janeiro: Forense Universitária, 2010.

. A promessa da política. Tradução Pedro Jorgensen Jr. Rio de Janeiro: Difel, 2008.

Entre o passado e o futuro. Tradução Mauro W. Barbosa de Almeida. São Paulo: Perspectiva, 1997.

. Origens do totalitarismo. Tradução Roberto Raposo. São Paulo: Companhia das Letras, 1989.

DELEUZE, Gilles. Foucault. Tradução Claudia Sant'Anna Martins. São Paulo: Brasiliense, 2006.

DELEUZE, Gilles, GUATTARI, Félix. Mil platôs: Capitalismo e Esquizofrenia. Volume 5. Tradução de Peter Pál Pelbart e Janice Caiafa. São Paulo: 34, 2012 a.

. Mil platôs: Capitalismo e Esquizofrenia. Volume 3. Tradução de Aurélio G. Neto, Ana Lúcia de Oliveira, Lúcia Cláudia Leão e Suely Rolnik. São Paulo: 34, 2012 b.

FOUCAULT, Michel. Vigiar e Punir: nascimento da prisão. Tradução Raquel Ramalhete. Petrópolis/RJ: Vozes, 2009. . Segurança, Território, População: curso dado no Collège de France (1977-1978). Tradução Eduardo Brandão. São Paulo: Martins Fontes, 2008. . O nascimento da clinica. Tradução de Roberto Machado. Rio de Janeiro: Forense Universitaria, 2001.

Em defesa da sociedade: curso no Collège de France (1975-1976). Tradução Maria Ermantina Galvão. São Paulo: Martins Fontes, 1999.

. Microfísica do poder. Organização e tradução Roberto Machado. Rio de Janeiro: Graal, 1979.

GUATARRI, Félix. As três ecologias. Tradução Maria C. F. Bittencourt. Campinas/SP: Papirus, 1990.

e ROLNIK, Suely. Micropolítica. Cartografias do desejo. Petrópolis/RJ: Vozes, 1999.

HARAWAY, Donna et alli. Antropologia do ciborgue. As vertigens do pós-humano. Belo Horizonte: Autêntica, 2009.

LATOUR, Bruno. Jamais fomos modernos. Tradução Carlos Irineu da Costa. São Paulo: 34, 2013.

LYRA, Edgar. "Hannah Arendt e a ficção científica". In: O que nos faz pensar, v. 20, n. 29, p. 97-122, maio 2011. Disponível em http://www.oquenosfazpensar.fil.puc-rio.br/index.php/oqnfp/article/view/330. Acesso em setembro de 2020.

MBEMBE, Achille. Brutalisme. Paris: La Découverte, 2020.

PAIVA, A. et alli. Rio sob intervenção: medo, percepção de risco e vitimização na cidade do Rio de Janeiro. São Paulo: FBSP e Datafolha, 2018.

RANCIÈRE, Jacques. "L'introuvable populisme”. In: BADIOU et alli. Qu'est-ce qu'um peuple? Paris: La Fabrique, 2013, pp. $137-143$.

. O desentendimento. Política e filosofia. Tradução Ângela Leite Lopes. São Paulo: 34, 1996.

ROUVROY, Antoinette, BERNS, Thomas. "Governamentalidade algorítmica e perspectivas de emancipação: o díspar como condição de individuação pela relação?”. Tradução Paulo Henrique Andrade. In: Revista Eco Pós, vol. 18, n.

2. Rio de Janeiro: UFRJ, 2015, pp. 36-56.

TELES, Edson. Ação política em Hannah Arendt. São Paulo: Almedina, 2019. 
"Governamentalidade algorítmica e as subjetivações rarefeitas". In: Revista Kriterion. Belo Horizonte: UFMG, ${ }^{\circ}$ 140, agosto 2018, pp. 429-448.

"A revolta dos tuiutis". In: Peixe Elétrico, fevereiro de 2018. Disponível em https://www.peixe-eletrico.com/singlepost/2018/02/23/A-revolta-dos-Tuiutis. Acesso em setembro de 2020.

UNO, Kuniichi. Guattari: confrontações. Conversas com Kuniichi Uno e Laymert Garcia dos Santos. São Paulo: n-1, 2016.

Recebido: 30/09/2020

Aprovado: 18/01/2021

Publicado: 31/01/2021 
